\title{
SUPPORTING DOCTORAL STUDENTS' SELF-DESCRIBED NEEDS WHILE ENROLLED IN A LIMITED-RESIDENCY INFORMATION SYSTEMS DOCTORAL PROGRAM
}

\author{
Steven R. Terrell, Nova Southeastern University, terrell@nova.edu \\ Michael F. Lohle, The University of Bridgeport, mlohle@bridgeport.edu
}

\begin{abstract}
Attrition rates for students in doctoral information systems programs average around 50\%; this rate can be higher in online and limited-residency programs. In order to identify risk factors that the administration and faculty might address proactively, prior research by the authors has focused on those issues identified by doctoral students successfully completing their degree, as well as students who left their program prior to graduation. This study continued this line of research by focusing on the perceived needs and attitudes of students while they were conducting dissertation research. Results indicate these students shared many of the same concerns identified by students in the earlier studies, and offered input on interventions necessary to address those concerns. The development and application of policies, procedures and tools based on results of this research may help administrators and faculty better address the needs of their students.
\end{abstract}

Keywords: Information Systems, Graduate School, Persistence, Best Practices

\section{BACKGROUND AND SIGNIFICANCE OF THE STUDY}

Historically, the attrition rate of doctoral students in traditional, on-campus programs has been $40 \%$ to $50 \%$ (Bowen \& Rudenstine, 1992; Litalien \& Guay, 2015; National Center for Educational Statistics, 2000; National Research Council, 1996; Smallwood, 2004), while attrition rates for distance-based programs (Rovai, 2002) and specifically, distance-based doctoral programs (Terrell, 2005a, 2005b, 2005c, 2012, 2015), can be $10 \%$ to $20 \%$ higher. In addition to limiting applicants for jobs where doctoral degrees are required, attrition wastes financial and temporal resources of the institution, faculty, and students (Gardner, 2010; Golde, 2005; Litalien \& Guay, 2015).

Studies have shown that the majority of doctoral students are capable of completing their degree and many of the barriers that students face pertain to institutional and program characteristics (Bowen \& Rudenstine, 1992; Golde 2005; Lovitts, 2001, 2008; Terrell, 2015). Prior research by the authors (Kennedy, Terrell \& Lohle, 2015; Terrell, Lohle \& Kennedy, 2016) has focused on the identification of policies, tools and instruction that students in the program feel would be beneficial and ultimately lead to greater success.

\section{PROBLEM STATEMENT}

The attrition rate of students in the information-systems limited-residency doctoral program at the university where the study was conducted is significantly higher (i.e., $60 \%$ to $70 \%$ ) than the $50 \%$ attrition rate of students in traditional doctoral programs.

\section{PURPOSE AND RESEARCH QUESTION}

The purpose of this study was to better understand the perceptions of students engaged in dissertation research while in a limited-residency information systems doctoral program. The study was guided by one overarching research question: How can students be better-prepared or supported while conducting dissertation research? 


\section{METHODOLOGY}

Prior to the onset of this study the researchers applied for and received IRB approval to proceed with the study as described. Students working on their dissertations at that time were then sent a recruitment letter and an informedconsent document; from these, 16 students agreed to participate in the study. At the outset, the researchers described the purpose and procedures of the study, the risks and benefits, confidentiality and privacy, as well as their right to withdraw from the study at any point. Students agreeing to participate were given an opportunity to ask any questions or share any comments or concerns they may have had prior to participation, after which they were emailed a link to an online survey asking for demographic data and a response to:

Due to the anonymity of the responses, the researchers felt that solely using students from their own department would not be problematic, thereby resulting in valid data.

\section{Open and Axial Coding}

Data analysis began with the open-coding of transcripts wherein the researchers read each sentence of the transcript and assigned a code reflective of the general ideas underlying the overall phenomenon of the text (Glaser \& Strauss, 1967). These codes represent the highest level of abstraction and allowed the researchers to identify axial codes based on one or more common themes within the open codes. The analysis concluded with the development of a selective code tying the axial codes into an overarching theme; this selective code is the source of the best practice emanating from this study. In this case, data saturation was researched after reading seven transcripts resulting in 46 open codes; during the process of axial coding, two meaningful codes were identified.

\section{Academic and Personal Support}

The initial analysis of the surveys led to the development of themes representing the needs of a given student, as well as over-arching academic support needs (i.e., meeting the needs of all students). While conceptually distinct, in many cases, overlap was evident; this led to a combination of these themes and the development of an overarching construct reflecting overall academic and support issues. Among others, persons surveyed described a need for clearer program and academic guidelines, better communication between students, faculty and staff, and workshops focused on specific topics. Comments subsumed under this category included:

It would be nice if we could have a short and simple step-by-step dissertation presentation hosted online.

I suggest creating a full template/sample for the Idea paper and the proposal for the students to follow.

A possible seminar (maybe required) that thoroughly reviews the Dissertation Guide along with a $Q \& A$.

Having a single go-to source (non-print, non-PDF) that is interactive and searchable would be really convenient

So constructing a series of workshops to support a student in developing the concept paper much earlier in the curriculum may be what I would suggest.

When I say substantive, I am talking about a workshop that has a deliverable where I must produce something - not just sitting through presentations.

Please take a few minutes to give me your thoughts on how we can better prepare or support students as they begin working on their dissertation.

I feel that instruction in the proper use of APA might be of significant value. 
It would be helpful to have a resource that could check Idea Papers, Dissertation Proposals, and Dissertation work for APA formatting

I suggest appointing a tutor for all Doctoral students. The tutor may help in reviewing the submissions before actually getting submitted to the Committee Chair.

I suggest creating a full template/sample for the Idea paper and the proposal for the students to follow.

Although I understand that each dissertation is different, and the process can vary from chair to chair, it would be helpful to have a general sequencelflowchart of events through the dissertation process, whether at the chair level or the degree level.

I think more focused seminars for each section of the dissertation document would have been helpful.

\section{Research Coursework Needed}

References to changes to the curriculum focused on a desire for additional research methods coursework, as well as workshops focused on specific aspects of research methods, data collection and analysis, etc.:

When I took the quantitative methods course, it started to make the dissertation process a bit more real, at least from the perspective of understanding that I would need to collect and analyze data. However, I then ended up with a purely qualitative study for which I basically was not prepared for.

Being able to have prior experience with using statistics would have been very helpful once the dissertation research had begun.

I would suggest including a minimum of two research courses in the program.

While the research courses offered much about foundations and theories of research, they did not provide opportunities for rigorously applying them. Reading about them is not the same.

I suggest including a course where students can start building the Idea Paper before completing their coursework.

It would be good for the curriculum to incorporate a required qualitative methods course... at least introduce approaches such as Delphi method, case study, etc., and perhaps even practice with tools such nVivo

Some other programs at other institutions have built-in milestones in the course work that actually allow students to produce some of the early dissertation documents, such as the idea paper or the lit review for the proposal. Perhaps this is something that could be included in the dissertation procedures

The same kind of activity needs to be done with the quantitative research methods course. It would have been helpful to actually apply some statistic measure or manipulate some sample data and talk about what conclusions could be drawn rather than just identify the types of studies.

I also would like to have examples of data and practical explanations of how to manage and analyze qualitative \& quantitative data. Such as offering a small set of data, walking through creating an actual code book, coding and themes. It would also be beneficial if there were explanations about what each statistical test tells a researcher and when and why you would use such as test. 


\section{The Expansion of Previously Published Best Practices}

In earlier studies (Kennedy, Terrell \& Lohle, 2015; Terrell, Lohle \& Kennedy, 2016), the researchers developed a set of best practices based on data collected during interviews with graduates from the same program (Appendix A). When the axial codes in the current study were examined, it was determined that the current students voiced many of the same concerns as graduates of the program. At the same time, many felt that the resources needed and described by the graduates of the program, could be expanded and should be offered in both online and face-to-face workshops. This includes topics such as the dissertation process itself, component parts of the dissertation document, and editing and formatting requirements.

The respondents placed more emphasis on additional requirements from the research coursework by reinforcing the call for more courses of this type while, at the same time, expanding on topics covered within these courses. Suggestions included embedding a research component in all courses, more attention paid to data collection and analysis, and a greater focus on an applied versus theoretical research component. Interestingly, the insight of these participants also mirrors that of students leaving the program prior to graduation (Terrell, Snyder, Dringus and Maddrey, 2012)

\section{CONCLUSIONS}

The purpose of this study was to identify factors that students currently working on their dissertation in a limitedresidency information systems doctoral program felt would have better prepared and supported them during that phase of their doctoral studies. The results substantiate the earlier work of the authors in establishing a set of best practices identified by graduates of the program. In this case, the respondents, most likely because they were working on their dissertations at the time of the surveys, further developed several of the themes uncovered in interviews with graduates of the same program. As noted, a heavy emphasis was placed on the need for better personal and material support, as well as additional research coursework and workshops.

As noted by Lovitts (2001) and others, attrition from doctoral degree programs is inevitable; up to $50 \%$ of students do not finish due to personal, financial or academic reasons. The development and application of policies, procedures and tools based on results of this research, however, may help administrators and faculty address the additional $10 \%$ to $20 \%$ they have historically experienced at the university where the research was conducted.

\section{REFERENCES}

Bowen, W. \& Rudenstine, N. (1992). In pursuit of the Ph.D. Princeton, NJ: Princeton University Press.

Ehrenberg, R., Jakubson, G.,Groen, J., So, E., \& Price, J. (2007). Inside the black box of doctoral education: What program characteristics influence doctoral students' attrition and graduation probabilities? Educational Evaluation and Policy Analysis, 29(2), 134 - 150.

Gardner, S.K. (2010). Contrasting the socialization experiences of doctoral students in high- and low- completing departments: A qualitative analysis of disciplinary contexts at one institution. The Journal of Higher Education, 81(1), $61-81$.

Glaser B. \& Strauss A. (1967) Discovery of grounded theory. Strategies for Qualitative Research. Mill Valley, CA: Sociology Press.

Golde, C.M. (2005). The role of the department and discipline in doctoral student attrition: Lessons from four departments. The Journal of Higher Education, 76(6), 669 - 700.

Groen, J.A., G. Jakubson, R. Ehrenberg, S. Condie \& A. Liu (2008). Program design and student outcomes in graduate education. Economics of Education Review, 27(2) 111-124. 
Kennedy, D., Terrell, S., \& Lohle, M. (2015). A grounded theory of persistence in a limited-residency doctoral program. The Qualitative Report, 20(3).

Litalien, D. \& Guay, F. (2015). Dropout intentions in PhD studies. A comprehensive model based on interpersonal relationships and motivational resources. Contemporary Educational Psychology, 41, 218-

Lovitts, B.E. (2001). Leaving the ivory tower: the causes and consequences of departure from doctoral study. Lanham, UK: Rowman \& Littlefield Publishers, Inc.

Lovitts, B. (2008). The transition to independent research: Who makes it, who doesn't, and why. The Journal of Higher Education, 79(3), 296 - 325.

National Center for Education Statistics. (2000). Percentage distribution of doctoral degree students according to selected student, enrollment, and employment characteristics, by type of degree: 1999-2000.

National Research Council. (1996). The path to the Ph.D.: measuring graduate attrition in the sciences and humanities. Washington, DC: National Academy Press.

Rovai, A. (2002). Development of an instrument to measure classroom community. The Internet and Higher Education, 5(3), 197-211.

Smallwood, S. (2004, January 16). Doctor dropout. The Chronicle of Higher Education. Retrieved March 18, 2005 from http://chronicle.com/prm/weekly/v50/i19/19a01001.htm

Terrell, S. (2005a). A longitudinal investigation of the effect of information perception and focus on attrition in online learning environments. The Internet and Higher Education, 8(3), $213-219$.

Terrell, S. (2005b). Supporting different learning styles in an online learning environment: does it really matter in the long run? Online Journal of Distance Education Administration, 8(2).

Terrell, S. (2005c). A longitudinal investigation of the effect of information perception and focus on attrition in online learning environments. Internet in Higher Education, 8(3).

Terrell, S., Snyder, M., Dringus, L. \& Maddrey, E. (2012). A grounded theory of connectivity and persistence in a limited residency doctoral program. The Qualitative Report, 17.

Terrell, S. (2015). Using hemispheric preferences as a predictor of success in a limited-residency information systems doctoral program. The Online Journal of Applied Knowledge Management, 2(1), 127-133.

Terrell, S., Lohle, M. \& Kennedy, D. (2016). Student-identified requirements for persistence in a limited- residency information systems PhD program. Online Journal of Applied Knowledge Management, 4(1).

U.S. Department of Education, Office of Planning, Evaluation and Policy Development (2009). Evaluation of evidence-based practices in online learning: A meta-analysis and review of online learning studies. Retrieved from http://www2.ed.gov/about/offices/list/opepd/ppss/reports.html 